It seems reasonable to believe that the possibility of replacing water by ammonia is not limited to the hydrate of the trivalent alcohol in question, and it seems even possible that other substances than ammonia capable of forming hydrogen bonds may build up structures corresponding to those of the hydrates. Further studies in this direction, now in preparation, may give valuable information concerning the properties of hydrogen bonds. Full details concerning the structure of the phloroglucitol diammoniacate will be published in Acta Chemica Scandinavica.

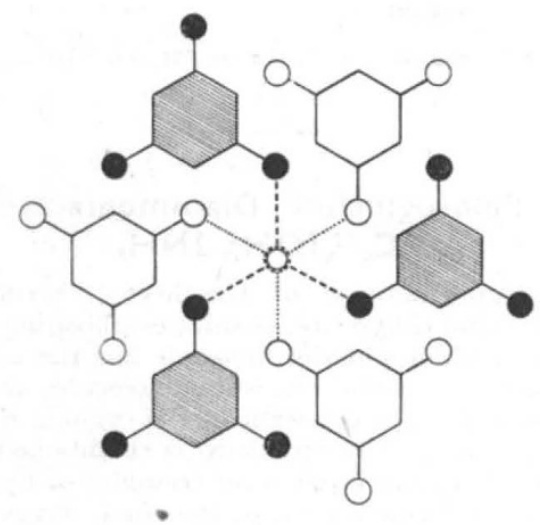

Fig. 1. Part of the $\mathrm{C}_{6} \mathrm{H}_{3}(\mathrm{OH})_{3} \cdot 2 \mathrm{NH}_{3}$ structure projected along

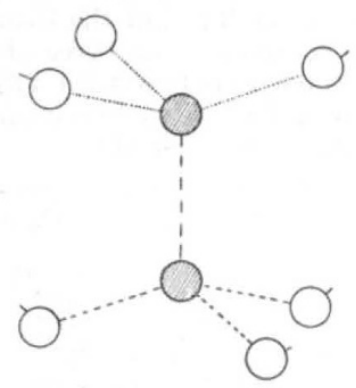

Fig. 2. The $\mathrm{O}_{3}-\mathrm{N}-\mathrm{N}-\mathrm{O}_{3}$ arrangement

In Fig. 1 part of the structure projected along the trigonal axis is reproduced; Fig. 2 shows the arrangement of the $\mathrm{O}_{3}-\mathrm{N}-\mathrm{N}-\mathrm{O}_{3}$ group.

PER ANDERSEN
$\begin{aligned} & \text { Oniversitetets Kjemiske Institutt, } \\ & \text { Blindern, Oslo. } \\ & \text { Oct. 26. }\end{aligned}$
${ }^{1}$ Andersen, Per, and Hassel, 0., Acta Chem. Scand., 2, 527 (1948).

\section{Structure of Polyglycine}

IN a preliminary report on a chemical, X-ray and infra-red investigation of synthetic polypeptides ${ }^{1}$, one of the forms of polyglycine was tentatively assigned a rectangular unit cell of dimensions : $a=4 \cdot 36 \mathrm{~A}$. (or twice that), $b \approx 7 \mathrm{~A}$., and $c=3 \cdot 44 \mathrm{~A}$. I should like now to correct this in the light of more recent considerations.

At a meeting in November 1948 of the X-Ray Analysis Group of the Institute of Physics, it was suggested by Bunn that polypeptides with shorter side-chains, and polyglycine in particular, might be expected to fit together in approximate close-packed arrangements like that found in the polyamides (nylons) ${ }^{2}$, in which, though the interplane spacing is $4 \cdot 36_{5} \mathrm{~A}$., the actual distance between chains bridged by $\mathrm{CO}$... NH hydrogen bonds is $4 \cdot 77 \mathrm{~A}$. Rudall, working in this laboratory, and reviewing in another connexion the types of packing in protein structures, has also lately directed my attention to the improbably high density (about $1.8 \mathrm{gm} . /$ c.c.) that would be required if polyglycine had the rectangular cell proposed. We had no density data at the time; but the density of a preparation of polyglycine film has now been measured ${ }^{3}$ and found to be close to $1.51 \mathrm{gm} . /$ c.c.

Taking Bunn's scheme and the same hydrogenbonded distance between chains as in nylon, together with the residue-length $\left(3 \cdot 67 \mathrm{~A}\right.$.) estimated by Corey ${ }^{4}$ for a completely extended polypeptide, the calculated density of polyglycine is

$$
\frac{57 \times 1.65}{4.77 \times 3.44 \times 3.67}=1.56 \mathrm{gm} . / \mathrm{c.c.},
$$

in satisfactory agreement with experiment. On this basis the $\beta$-angle is $\sin ^{-1} 4 \cdot 36 / 4 \cdot 77=66^{\circ}$; also, of course, practically the same as the corresponding angle in nylon.

The special importance of this result is in relation to the infra-red data ${ }^{1}$, which show that in spite of substantial variations in backbone spacing, the $\mathrm{CO}$... NH linkage remains virtually unchanged. Bunn's interpretation would be to keep a fairly constant inter-chain backbone distance (round about $4 \cdot 77 \mathrm{~A}$.) and let the $\beta$-angle increase with increasing side-chain distance until in $\beta$-keratin, for example, where the backbone spacing is $4.65 \mathrm{~A}$., the cell becomes approximately rectangular (as direct observation shows ${ }^{5}$ ); and there seems little doubt now that this view is sound as regards polyglycine at least. Whether it is generally valid for polypeptides with longer side-chains-and there are evident difficulties at the moment - must await the results of calculations from density data not yet available.

Department of Biomolecular Structure,

W. T. Astbury

University of Leeds. April 4.

1 Astbury, W. T., Dalgliesh, C. E., Darmon, S. E., and Sutherland, G. B. B. M., Nature, 162, 596 (1948).

${ }^{2}$ Bunn, C. W., and Garner, E. V., Proc. Roy. Soc., A, 189, 39 (1947).

${ }^{3}$ Dalgliesh, C. E. (private communication).

“Corey, R. B., Chem. Rev., 26, 227 (1940).

${ }^{5}$ Astbury, W. T., and Sisson, W. A., Proc. Roy. Soc., A, 150, 533 1935, ; Astbury, W. T., and Dickinson, S., Proc. Roy. Soc., B,

\section{Refining of Oils Containing Vitamin A}

THE alkali-refining of fish liver oils containing vitamin $A$ has, in the last few years, acquired increased importance due to the development of molecular distillation. This method of distilling, while yielding concentrates of a high vitamin A content, requires, in order to obtain satisfactory results, oils free from impurities and with low acid-values. Alkali-refining provides the best means of satisfying this requirement; but it has been considered that a treatment of this kind decreases the potency of vitaminic oils because of the adsorption of vitamin A by soaps formed in situ ${ }^{1}$. 